\title{
Large Decompressive Craniectomy in Management of Severe Cerebral Contusion. A Review of 207 Cases
}

\author{
Akira Yamaura, Kenichi Uemura* and Hiroyasu Makino \\ Department of Neurological Surgery, \\ Chiba University School of Medicine, \\ Inohana-cho, Chiba-shi, Japan
}

\begin{abstract}
Summary
Since 1966, large decompressive craniectomy has been performed in acute severe cerebral contusion with or without concomitant intracranial hematomas. A total of 207 cases have been treated up to this time and short-term and long-term follow-up studies have been conducted. The long-term follow-up study of children and adults in Series 1 of 154 patients showed $17 \%$ and $33 \%$ mortality and $100 \%$ and $73 \%$ functional recovery rates, respectively. Prognosis was markedly different for patients under and over 30 years of age. Prognostic key signs of pupillary changes, decerebration and respiratory disturbance, and grading of the above factors were confirmed to be practical and reliable guidelines in forecasting surgical outcome. The accuracy of the grading system was tested in Series 2, which consisted of 53 more recent cases.

In spite of the development of various methods for treatment of severe head injury, decompressive craniectomy is stressed as being indispensable if the appropriate time for surgery is not missed.
\end{abstract}

Key words: Decompressive craniectomy, cerebral contusion acute head injury, acute brain swelling

\section{Introduction}

In the management of serious head injury, it had been the general policy for most neurosurgeons to detect intracranial hematoma using all kinds of modern diagnostics and to evacuate them as soon as possible. From this classical concept, multiple burr holes or ordinary osteoplastic craniotomy were most widely used. However, it is now apparent from the dismal results of acute subdural hematoma, with extremely high mortalities of some 70 to $90 \%$ in many reported series, that this classical surgical policy has completely failed in the treatment of severe head injury. $8,18,25)$

Why have these techniques failed in saving

*Dr. K. Uemura is now at the Department of Neurological Surgery, Hamamatsu University School of Medicine, Hamamatsu. such serious patients? The answer may be found in the following facts. The purpose of these small openings was to evacuate hematomas and the evacuation was very often incomplete, leaving a not negligible amount of clot or even bleeding points undetected. Secondly, a majority of patients have not died of intracranial hematomas itself, but rather have died of underlying cerebral contusion or laceration, with inevitable extensive cerebral edema. Few neurosurgeons have focused attention to this problem, except for the recent development of adjunctive therapy, such as the use of steroid, mannitol, barbiturates, or hyperventilation.

Since 1966, unilateral or bilateral, extensive decompressive craniectomy has been performed as the method of choice to manage the raised intracranial pressure, which cannot be controlled by simply evacuating concomitant intracranial hematomas. ${ }^{14,15,16,17,33,34)}$

In this paper, two series totaling 207 cases 
were analyzed in an investigation of the effect of decompressive craniectomy in cases of severe cerebral contusion.

\section{Materials and Methods}

Large decompressive craniectomies were performed on patients whose consciousness were impaired with rapid and progressive deterioration, and/or with appearance or deterioration of other neurological deficits. Cerebral angiography was not the routine measure to decide the operation, because this kind of decompressive craniectomy is only effective when performed at the most appropriate time. A single dose of mannitol was infused during a waiting period prior to the surgery, but not used after decompressive craniectomy. Steroid was used post-operatively if there was no contraindication. The surgical technique was uniform in that a large bone flap over the cerebral contusion was removed and the dura mater was widely incised, anticipating a full decompressive effect. If this unilateral opening did not seem to be sufficient in its decompressive effect, a contralateral craniectomy was added. Such bilateral procedures were conducted in $24 \%$ of Series 1 .

This analysis is based on two series of a total of 207 cases, which were treated using the same policy $^{33)}$ at Chiba University Hospital and its three affiliated hospitals. Series 1 is composed of 154 patients (118 adults and 36 children), operated on between June 1966 and December 1974. A long-term follow-up study was conducted on these patients to trace their social recovery. The period from operation to followup study averaged 50 months, the longest being 10 years. Between January 1975 and December 1976 , a further 53 patients (40 adults and 13 children) were operated on and are summarized as Series 2. With regard to the latter 53 patients, postoperative mortality is discussed and the prognostic value of the data obtained in analysis of Series 1, was tested to determine its accuracy.

The outcome of the operated patients was analyzed in relation to the three key signs of pupillary changes, decerebration, and respiratory disturbance, which were used as preoperative scales. The presence or absence of these key signs were noted and recorded with certainty by either medical or co-medical staff. Grading of the preoperative neurological status of each patient was defined as follows: Grade I-None of the key signs were noted; Grade II-One of the key signs was noted; Grade III--Two of the key signs were noted; and Grade IV-All of the key signs were present. This grading system was found to be a simple and practical method for classification of the patients' preoperative condition.

In the analysis of the long-term follow-up, the patients were classified into the following six categories of social recovery: Grade A-Patient returned to his previous job (housewife to full activity at home, student to school in the appropriate grade, and child to normal activity for his age group); Grade B - Patient returned to a less demanding job, but was gainfully employed; Grade C-Patient was confined to home, but was able to care for self $\left(C_{1}\right)$, or was bedridden or unable to care for self $\left(C_{2}\right)$; Group $\mathrm{V}$-Patient was in a vegetative state under chronic hospital care; Group D-Patient was dead; and Group ?-Patient was discharged in good condition, but was loss to follow-up. Group A and B were considered as "functional recovery" or "returned to useful life."

\section{Result}

General statistics: Of total 154 Series 1 patients including children and adults, there were 45 deaths; a mortality rate of $29 \%$ (Table 1). Eighty survivors were followed, and 66 cases of $83 \%$ of them were in the category of "functional

Table 1 Results of long-term follow-up study of 154 patients in Series 1. (1966-1974)

\begin{tabular}{|c|c|c|c|c|}
\hline & & Adults & Children & Total \\
\hline A & $\begin{array}{l}\text { returned to } \\
\text { previous job }\end{array}$ & 30 & 27 & 57 \\
\hline $\mathrm{B}$ & $\begin{array}{l}\text { returned to } \\
\text { less demand- } \\
\text { ing job }\end{array}$ & 8 & 1 & 9 \\
\hline $\mathrm{C}_{1}$ & caring for self & 4 & - & 4 \\
\hline $\mathrm{C}_{2}$ & $\begin{array}{l}\text { need care of } \\
\text { family }\end{array}$ & 7 & - & 7 \\
\hline V & vegetative & 3 & - & 3 \\
\hline $\mathrm{D}$ & dead & 39 & 6 & 45 \\
\hline \multirow[t]{2}{*}{$?$} & $\begin{array}{l}\text { survived, but } \\
\text { lost in } \\
\text { follow-up }\end{array}$ & 27 & 2 & 29 \\
\hline & & 118 & 36 & 154 \\
\hline
\end{tabular}


recovery" (Groups A and B) and 14 cases or $18 \%$ were in the category of "unemployed" (Groups $\mathrm{C}_{1}, \mathrm{C}_{2}$, and $\mathrm{V}$ ), including 3 patients in vegetative states for 2 to 10 years. In the more recent series of 53 patients, there were 30 postoperative deaths, a mortality rate of $57 \%$, which was definitely larger than in Series 1. Under the same surgical policy, this unequivocal difference in mortality rates of the two series might give an odd impression. This, however, is clarified later in the analysis and in the testing of the prognostic value of the preoperative neurological grading. From both series of 207 patients, total deaths numbered 75 , a mortality rate of $36 \%$.

Age: "Age" is the most important "noncerebral" factor in discussing the outcome of serious head injury. The age distribution was from 5 months to 75 years, the mean age being 27 years at the time of decompressive craniectomy in Series 1. The patients were classified into pediatric age group and adult, according to the ordinary definition (Table 2). Seventeen per cent of the children and $33 \%$ of the adults died following decompressive craniectomy, the mortality of adults being twice as high as that of children $(p<0.05)$. There were no deaths among 8 children who were operated on in the first 24 months of life. All of the children who survived were not confined to home or hospital later, and all returned to their pre-morbid activities except one who entered a school for the mentally handicapped. Children had signifi- cantly higher chances of functional recovery than adults $(p<0.01)$. Only 7 children were still of pre-school age at the time of the follow-up study. The break point of age seemed to be at 30 years; those younger than 30 showed significantly favorable outcome in survival $(p<0.05)$ and functional recovery $(\mathrm{p}<0.01)$ (Table 3 ). There were 4 patients in their 70's and all of them eventually died; three of them were in a vegetative state for more than 3 months ( 2 of them were in a state of akinetic mutism) and died of complications. The other one died of direct cerebral effect on the 22nd day following surgery. In Series 2, there were 4 more patients in their seventies. Three died of complications between 3 weeks and 16 months from surgery and the other was bed-ridden in a disabled condition for more than 12 months. The outcome of the patients in the 70's seemed to be desperate. Between the age of 40 and 70 , there were no significant differences in their outcome. Key signs: The mortality rate with regard to each key sign from an analysis of Series 1 is presented in Table 4. In adults, the presence of any key sign resulted in significantly high mortality $(\mathrm{p}<0.01)$ and in children, none of the key signs was associated with significantly high mortality. Functional recovery of adults was also analyzed in relation to the presence of each key sign (Table 5). In the presence of any key signs, there was significantly less chance of functional recovery $(p<0.01)$. Among the three key signs, the presence of decerebration and respiratory

Table 2 Prognosis in relation to age. Patients were classified into two groups $(0-14 y$ and $<15 y)$. (Series 1$)$

\begin{tabular}{crc}
\hline & $\frac{\text { Mortality }}{2}$ & $\begin{array}{c}\text { Number of } \\
\text { patients }\end{array}$ \\
\hline $0 \sim 14 \mathrm{y}$. & Deaths & 36 \\
$15<$ & $6(17 \%)$ & 118 \\
\hline Overall & $39(33 \%)$ & 154 \\
\hline
\end{tabular}

Functional Recovery

\begin{tabular}{cccc}
\cline { 2 - 3 } Age & $\mathrm{A}+\mathrm{B}$ & $\mathrm{C}_{1}+\mathrm{C}_{2}+\mathrm{V}$ & $\begin{array}{c}\text { Followed } \\
\text { survivors }\end{array}$ \\
\hline $0 \sim 14 \mathrm{y}$. & $28(100 \%)$ & 0 & 28 \\
$15<$ & $38(73 \%)$ & $14(27 \%)$ & 52 \\
\hline Overall & $66(82.5 \%)$ & $14(17.5 \%)$ & 80 \\
\hline
\end{tabular}


Table 3 Prognosis in relation to age. Patients were divided into two groups $(0-29 \mathrm{y}$ and $<30 \mathrm{y})$. (Series 1$)$

\begin{tabular}{|c|c|c|c|}
\hline \multirow[b]{2}{*}{ Age } & \multicolumn{2}{|c|}{ Mortality } & \multirow[b]{2}{*}{$\begin{array}{l}\text { Number of } \\
\text { patients }\end{array}$} \\
\hline & \multicolumn{2}{|c|}{ Deaths } & \\
\hline $0 \sim 29 \mathrm{y}$ & \multicolumn{2}{|c|}{$22(23 \%)$} & 97 \\
\hline $30<$ & \multicolumn{2}{|c|}{$23(40 \%)$} & 57 \\
\hline Overall & \multicolumn{2}{|c|}{$45(29 \%)$} & 154 \\
\hline \multirow[b]{2}{*}{ Age } & \multicolumn{2}{|c|}{ Functional Recovery } & \multirow[b]{2}{*}{$\begin{array}{l}\text { Followed } \\
\text { survivors }\end{array}$} \\
\hline & $\mathbf{A}+\mathbf{B}$ & $\mathrm{C}+\mathrm{V}$ & \\
\hline $0 \sim 29 \mathrm{y}$ & $54(92 \%)$ & $5(8 \%)$ & 59 \\
\hline $30<$ & $12(57 \%)$ & $9(43 \%)$ & 21 \\
\hline Overall & $66(82.5 \%)$ & $14(17.5 \%)$ & 80 \\
\hline
\end{tabular}

Table 4 Key signs and mortality rate

\begin{tabular}{cccc}
\hline Key signs & Pupillary changes & Decerebration & Respiratory disturbance \\
\hline Children & $4 / 22(18 \%)$ & $2 / 9(22 \%)$ & $2 / 5(40 \%)$ \\
Adult & $32 / 73(44 \%)^{*}$ & $16 / 21(76 \%)^{*}$ & $11 / 15(73 \%)^{*}$ \\
\hline
\end{tabular}

*The presence of sign showed significantly high mortality. Series 1.

Table 5 Key signs and functional survival in adults (Series 1)

\begin{tabular}{lccc} 
Key signs & Pupillary changes* & Decerebration* & Respiratory disturbance* \\
\hline Present & $15 / 56(27 \%)$ & $2 / 21(10 \%)$ & $1 / 15(7 \%)$ \\
Absent & $19 / 29(66 \%)$ & $36 / 70(51 \%)$ & $32 / 65(49 \%)$ \\
\hline
\end{tabular}

functional survival: $\mathbf{A}+\mathbf{B}$ /followed survivor + dead

*significant

(Series 1)

disturbance were correlated with the poorest outcome in survival and functional recovery in adults.

Among the various pupillary changes, the poorest outcome was seen in cases with bilateral dilated and fixed pupils or with dilated fixed pupil and contralateral pinpoint pupil, with mortality rates of $75 \%$ and $85 \%$, respectively, in adults. Only 3 among 32 patients with such pupils recovered up to the level of functional recovery and all of them were younger than 30 years.

The presence of unilateral or bilateral decerebration resulted in mortalities of $57 \%$ or $86 \%$ and functional recovery of only $14 \%$ or $7 \%$, respectively in adults. There were only 2 patients who recovered up to the level of Group A: one with unilateral and the other with bilateral decerebration. They were both young (19 and 23 years), were operated on early, and they regained consciousness after 4 months and 27 days, respectively. The latter case required bilateral decompressive craniectomy. Two children with bilateral decerebration survived and are well.

In adults, patients showing respiratory disturbance had the poorest outcome. None of the 15 patients with this key sign returned to their previous jobs. Only one patient, a 20 -year-old male, who had undergone bilateral decompression within 4 hours, returned to a less demanding job after discharge from the hospital where he was unconscious for 4 months after operation. All of the others died or were disabled. Two apneic patients, 18 and 42 years old, in Series 1 were operated on within 2 and 12 hours, 
respectively, but neither survived more than 48 hours postoperatively. In Series 2, there were 3 apneic patients including one child and all of them took a similar course to death.

Grading of preoperative status: Adult patients in Series 1 were classified into 4 groups according to a preoperative status grading (Table 6). Grade I patients were operated on because of deepening of unconsciousness, appearance or deterioration of hemiparesis, or the presence of intracranial hematoma in cerebral angiography, but they did not show any of key signs before surgery. Ninety percent of them survived and $83 \%$ returned to useful life. The survival rate and functional recovery regressed steadily with declining preoperative grading. In Grade III, 9 of 27 patients survived and only 3 of them returned to useful life. All the 3 patients were under the age of 30 . In Grade IV, the number of patients was small, but only 1 survived in a vegetative state and all the others died within
48 hours of surgery. Patients in Grades III and IV or with more than two key signs, particularly those over the age of 30 , inevitably seemed to have poor prognoses.

Even in children, Grade IV resulted in a very poor survival rate. As shown in Fig. 2, 6 of 8 children from Series 1 and 2 died and one survivor is under chronic hospital care and the other is the only survivor with functional recovery. The 6 survivors from among 8 children of Grade III in Series 1 and 2 and the quality of the survival in the follow-up study were excellent in Series 1. There was no significant difference in distribution of grading between adults and children.

Prognostic value of preoperative grading: The postoperative mortality rate was tested using the probability obtained in Series 1 (Table 7). All patients were treated under the same surgical policy in Series 1 and 2, but more patients in the latter were operated on earlier (see, time

Table 6 Grading of preoperative status and prognosis (Series 1, Adults)

\begin{tabular}{lccc}
\hline & Number of patients & Survivors & Gainfully employed \\
\hline Grade I & 42 & $38(90 \%)$ & $24(83 \%)^{*}$ \\
Grade II & 45 & $31(69 \%)$ & $11(73 \%)^{*}$ \\
Grade III & 27 & $9(33 \%)$ & $3(43 \%)^{*}$ \\
Grade IV & 4 & $1(25 \%)$ & 0 \\
\hline
\end{tabular}

*gainfully employed/followed survivors

Table 7 Grading of preoperative status and mortality. Tested in Series 2, based on the data obtained in Series 1 .

\begin{tabular}{|c|c|c|c|}
\hline Grade & Patients & Expected death & Death \\
\hline \multicolumn{4}{|c|}{ Adults } \\
\hline I & 6 & 1 & 1 \\
\hline II & 9 & 3 & 2 \\
\hline III & 12 & 8 & 7 \\
\hline \multirow[t]{2}{*}{ IV } & 13 & 10 & 13 \\
\hline & $\overline{40}$ & $\overline{22}$ & $\overline{23}$ \\
\hline & \multicolumn{2}{|c|}{ Children } & \\
\hline I & 3 & 0 & 1 \\
\hline II & 1 & $\mathbf{0}$ & 0 \\
\hline III & 3 & 1 & 1 \\
\hline \multirow[t]{2}{*}{ IV } & 6 & 5 & 5 \\
\hline & $\overline{13}$ & $\overline{6}$ & $\overline{7}$ \\
\hline
\end{tabular}


elapse from impact to surgery) and there was a slight decrease in the number of head injuries caused by traffic accidents in Series 2. Otherwise there were no significant differences between the two series of patients. In this regard, Series 2 was considered to be an appropriate model group for testing the prognostic value of grading. Among 40 adults in various grades, 22 were expected to follow a path to death. Actual deaths totalled 23. Similarly, 6 children were expected to die among 13 patients and actual deaths totalled 7.

Hemiparesis and concomitant intracranial hematoma: Hemiparesis and concomitant intracranial hematoma are undoubtedly important signs in evaluating head-injury patients, but those signs were not included as prognostic landmarks among the key signs. In adults from Series 1 , the presence of hemiparesis did not have any significant influence on mortality and functional recovery (Table 8 ). In children, when appearance of hemiparesis was one of the factors in determining indication of operation, such patients had better outcome in mortality and functional recovery, but this was not statistically significant. The side of hemiparesis was also analyzed with regard to survival quality, but this did not cause any significant differences.

Concomitant intracranial hematomas were present in $67 \%$ of children and $71 \%$ of adults from Series 1. The presence of hematomas showed quite similar and non-significant influence on outcome in adults and children. When surgery is performed without the presence of hematoma, the outcome seemed to be poorer in children, but this was not significant. Among the variety of hematomas, acute subdural hematoma in adults was associated with a high mortality of $43 \%$ and a low functional recovery of $24 \%$, the latter being significant $(p<$ 0.01 ).

Time elapse from impact to surgery: Within 6 hours of head injury, operations were performed

Table 8 Hemiparesis and hematoma in relation with prognosis

Hemiparesis and prognosis

\begin{tabular}{|c|c|c|c|c|}
\hline \multirow[b]{3}{*}{ Present } & \multicolumn{2}{|c|}{ Mortality } & \multicolumn{2}{|c|}{ Functional recovery } \\
\hline & \multicolumn{4}{|c|}{ Adults } \\
\hline & $22 / 74$ & $(30 \%)$ & $22 / 53$ & $(42 \%)$ \\
\hline \multirow[t]{2}{*}{ Absent } & $13 / 38$ & $(34 \%)$ & $12 / 30$ & $(40 \%)$ \\
\hline & \multicolumn{4}{|c|}{ Children } \\
\hline Present & $3 / 27$ & $(11 \%)$ & $23 / 26$ & $(88 \%)$ \\
\hline Absent & $2 / 8$ & $(25 \%)$ & $5 / 7$ & $(71 \%)$ \\
\hline
\end{tabular}

Hematomas and prognosis

\begin{tabular}{rrrrrr} 
& \multicolumn{1}{l}{ Mortality } & \multicolumn{2}{c}{ Functional recovery* } \\
\cline { 2 - 6 } & \multicolumn{5}{c}{ Adults } \\
\cline { 2 - 6 } Present & $27 / 84$ & $(32 \%)$ & $30 / 68$ & $(44 \%)$ \\
\hline Absent & $12 / 34$ & $(35 \%)$ & $8 / 23$ & $(35 \%)$ \\
\hline & & & Children & \\
\hline Present & $3 / 24$ & $(13 \%)$ & & $20 / 23$ & $(87 \%)$ \\
\hline Absent & $3 / 12$ & $(25 \%)$ & $8 / 11$ & $(73 \%)$ \\
\hline
\end{tabular}

*functional recovery: $A+B /$ followed survivors + dead (Series 1) 
in $43 \%$ of Series 1 and $52 \%$ of Series 2 patients. Mortality rate was not related to time elapse if operations were performed within 24 hours in adults and 12 hours in children. The mortality rate, however, decreased in patients operated on later than 24 hours in adults and 12 hours in children. Patients in Grades I and II only were operated on later than 24 hours of head injury and this may be one of the reasons for the good results (Figs. 1 \& 2). However, attention should be paid to 4 patients with good preoperative grading who died after late operation. Unduely delayed decompressive craniectomy could not save such patients even in the absence of the

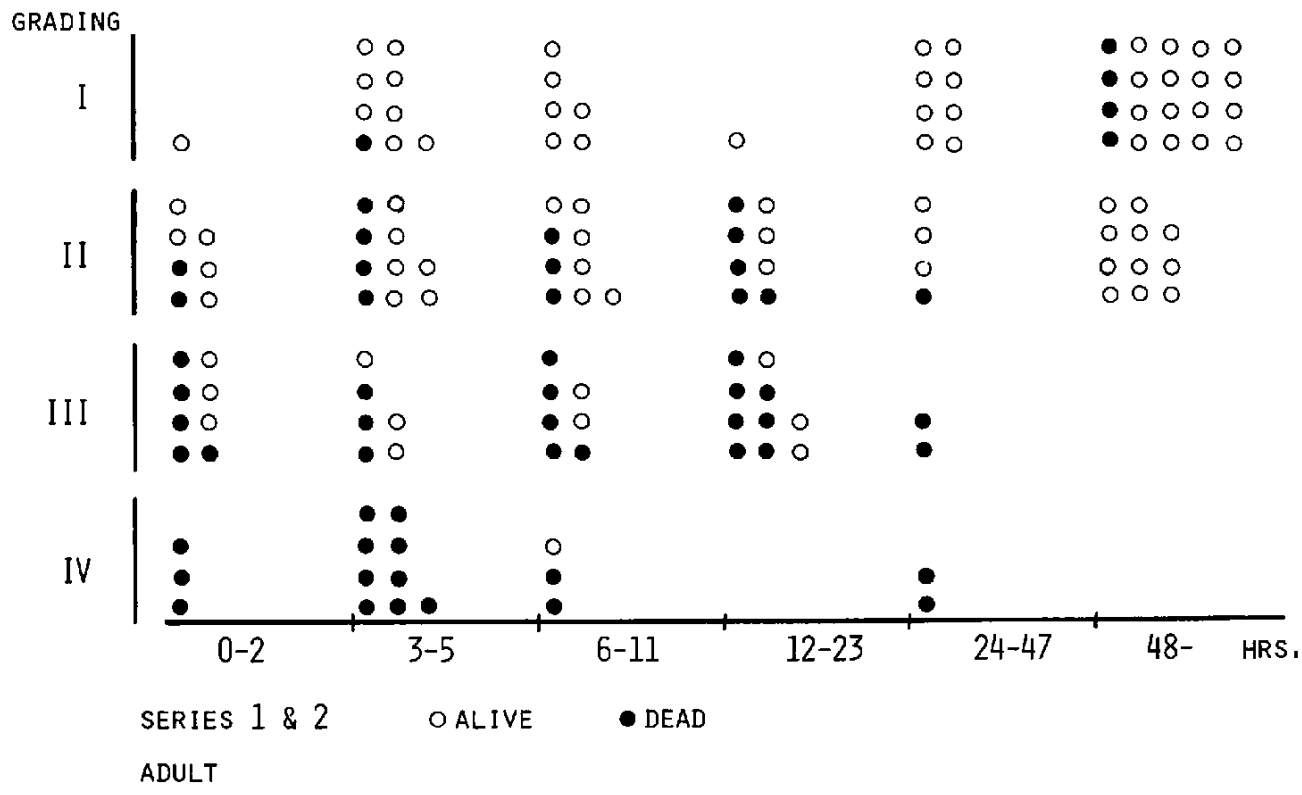

Fig. 1 Mortality in relation with grading and timing of decompression. Adults from Series 1 and 2.

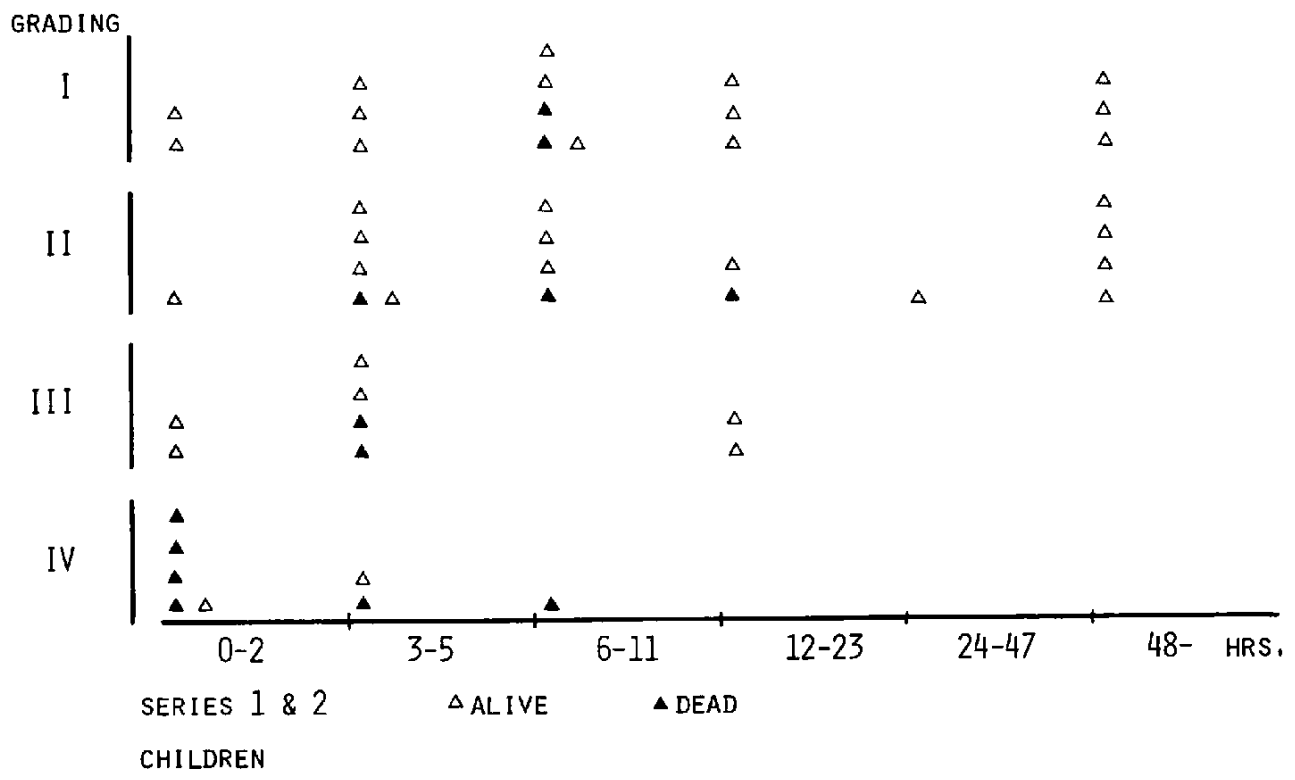

Fig. 2 Mortality in relation with grading and timing of decompression. Children from Series 1 and 2. 
key signs. Operative indication should be decided from any deterioration of consciousness level or appearance of other neurological deficits at an appropriate time.

Acute brain swelling: If acute brain swelling is defined as rapid and remarkable bulging of the traumatized brain during craniotomy, it was observed in $2(15 \%)$ of 13 children and $5(13 \%)$ of 40 adults in Series 2, and all of these patients died within 4 days of surgery. Seven such cases with acute brain swelling were reviewed in a search for any specific signs preceding this tragedy. The age distribution was 2 to 69 years and 6 of them were Grade III or IV preoperatively. Time elapse from impact to surgery did not particularly differ from that of the statistics described above, and intracranial hematoma was absent in 3 of them. A unique case was a 2-year-old child who was operated on within 8 hours and the preoperative status was Grade I: he expired at 8 hours after occurrence of acute brain swelling. In this particular case, there were no detectable signs which suggested appearance of this phenomenon.

\section{Discussion}

In treatment of acute severe head injury, it has been our belief that the primary importance is the presence of direct brain damage in the form of contusion or laceration, which inevitably causes massive edema, resulting in intracranial displacement or intracranial hypertension. We have selected extensive decompressive craniectomy as the method of choice to control raised intracranial pressure, which cannot be well controlled, by simply evacuating concomitant hematomas. This surgical policy has not been modified for the last 10 years. ${ }^{14,15,16,17,33,34)}$

Large series of autopsy cases after fatal head injury have revealed the presence of contusion or laceration in 76 to $87 \%$ of the cases, whereas, intracranial hematomas without significant brain damage were observed in only 10 to $16 \%{ }^{1,27)}$ Observation of bilateral cerebral involvement is also extremely common in neurosurgical practice. Ransohoff and Randt ${ }^{23}$ ) comfirmed striking bilateral edema in 11 of 18 fatal head injuries. According to observations by Courville, ${ }^{4)}$ the incidence of contrecoup injury in children came close to that of adults if a child is more than 4 years old. Recent de- velopment of computed tomography has revealed the presence of bilateral cerebral involvement in $35 \%$ of serious head injuries from a large German cooperative study series. ${ }^{7}$ In our experience, bilateral decompressive craniectomy was required in 31 of 118 adults and in 6 of 36 children of Series 1 .

Concerning the operative technique of decompressive craniectomy, our principle since 1966 has been to make a large bony opening over the contused brain. This may be unilateral or bilateral, and the bone flap is usually turned over the fronto-temporo-parietal region, leaving the occipital region intact to support the decompressed cerebral hemispheres. A narrow bone bridge over the superior sagittal sinus is also left to prevent unnecessary blood loss and to serve as a supportive structure in cranioplasty. It is of crucial importance to rongeur the temporal bone down to the level of the middle fossa. The bone flap is discarded or is buried under the skin of the thigh to keep the bone flap well nourished until cranioplasty. In the literature, Kerr introduced a similar technique as a radical method for decompression and has criticized a variety of conventional techniques with regard to the incomplete decompressive effects. ${ }^{11)}$ His suggestion was that by this bilateral craniectomy, expansion of brain would occur away from the midbrain towards both sides, thus providing maximal relief of pressure at this vital point and preventing unfavorable distortion of the brain secondary to unilateral decompression. In this regard, the proposal of Ransohoff et al., ${ }^{24)}$ who have performed uniform hemicraniectomy on patients with angiographically confirmed unilateral acute subdural hematoma appears unacceptable. It is our experience that even if a massive subdural hematoma is revealed on the one side, an extensive contusion or laceration is not ruled out on the opposite hemisphere and the surgeon should be ready to perform a contralateral procedure if the brain does not become sufficiently relaxed during the unilateral operation. In the second series of Ransohoff, ${ }^{3)}$ the results were disappointing, with only a $10 \%$ total survival rate and a $4 \%$ functional survival rate, although many of their patients were too seriously damaged at the time of impact to be successfully treated by any method. Only 3 $(5 \%)$ of 60 patients, treated with a large cranio- 
tomy by Fell, ${ }^{6)}$ returned to work, whereas $18 \%$ were employable after bifrontal decompressive craniectomy in the series of Venes and Collings. ${ }^{32)}$

In order to determine the prognosis of serious head injury, many authors have been advocating a wide variety of pre-operative clinical, physiological and neuroradiological variables as prognostic landmarks. ${ }^{3,22,23,25,30,31)}$ Monitoring of intracranial pressure is now a routine measure in many hospitals for treatment of head injury. We have selected only three clinical variables as prognostic key signs. The presence or absence of each key sign was based on clear-cut observation by the medical staff. This method was confirmed to be practical and useful in forecasting the outcome under the surgical policy of large decompressive craniectomy. The level of consciousness is undoubtedly an important index for determining the severity of head injury. Talalla and Morin ${ }^{30)}$ noted a correlation between the pre-operative conscious state of the patients and their ultimate outcome. However, it is extremely difficult to record the state of consciousness in a universally acceptable terminology, which is conducive to strict comparison among various institutes or even among the medical staffs in the same hospital. This is one of the reasons why the standarized grading of 3-3-9 method was proposed in our country. This seemingly acceptable scoring has recently been criticized from a statistical viewpoint ${ }^{28 \text { ) }}$ and may share the difficulties of evaluation in cases of aphasia or apraxia, which are found in conventional methods. Consciousness was invariably impaired in our patients, but we have not used this controversial factor as a prognostic key sign for fear of detracting from the relatively a objective findings of the other key signs. Cooper et al. $^{3)}$ also did not include conscious state in their numerical quantitation. They found that presence of hemiparesis did not have any significant influence on outcome and involvement of the dominant or nondominant hemisphere did not alter the survival rate or social recovery in a longterm observation. Also angiographically recognized or operatively confirmed intracranial hematomas were not selected as a guideline for prognosis. Other than age, pupil, motor response and respiration, Overgaard et al. ${ }^{22)}$ stressed the importance of post-traumatic high blood pressure as an un- favorable sign in relation to quality of survival. Vapalathi and Troupp, ${ }^{31)}$ on the other hand, observed that in the presence of very low $\mathrm{PaCO}_{2}$ with spontaneous breathing, the outcome of the patients was death or a vegetative state, Cooper et al. gave 30 points to motor examination, 20 to respiration, 30 to pupillary responses, 10 to oculocephalic reflexes, and 10 to corneal reflexes. ${ }^{3)}$ Becker et al. studied decerebration, pupillary abnormality and oculocephalic responses in addition to observation of intracranial pressure and tried to compare their results with those of other institutes. ${ }^{2)}$ Comparison of results in different series is only possible in the presence of a common preoperative scale. The forecasting scale of Sano et al. ${ }^{27)}$ was based on careful statistical preparation, but our actual results ${ }^{33}$ ) were far better than what was expected from the indices. This might be due to the difference of treatment methodology. Under a surgical policy unmodified for more than 10 years, the expectation of survival rate was surprisingly accurate in our two series with use of such simple grading.

In the field of non-surgical treatment of severe head injury, more recent advances and those still in need of confirmation include cerebral dehydration by hypertonic solution of urea, mannitol, gycerol, or most recently by hypertonic lactate solution, ${ }^{29)}$ use of steroids, hyperbaric oxygen therapy, CSF alkalizing agents, barbiturates, hypothermia and controlled hyperventilation. In our series, steroids were used for 1 to 2 weeks and $1-3 \mathrm{gm} / \mathrm{kg}$ of $20 \%$ mannitol was infused preoperatively, when necessary.

Since the pioneer studies in monitoring intracranial pressure by Janny (1951) and Lundberg (1960), more than 15 years have elapsed. Jennett ${ }^{10)}$ summarized its history and he concluded that the indication of monitoring lies in two points - one in clinical and the other in research. He stated that the former application, that is the role of intracranial pressure in prognosis, especially after head injuries, was perhaps less important than it once seemed. It is notable, however, that at the time of his review, Jennett had not used such monitoring for 6 months. He admitted that measurement of intracranial pressure was not straightforward even at the present time. From experiences reported by various institutes, monitoring of 
intracranial pressure might offer an adequate index for determining the immediate effects of therapy, but it does not seem to offer any reliable data concerning social recovery. Although monitoring of intracranial pressure has been widely used throughout the world, it should be critically evaluated as to whether or not the benefits obtained by its use outweighs the cost in time, efforts and money required for its daily use.

Under intracranial pressure monitoring, a widely used adjunctive therapy is 'controlled hyperventilation'. This technique was originally introduced from the concept of reactivity of vascular bed to hypocapnea, resulting in a smaller intracranial vascular bed and lowered intracranial pressure. Control of intracranial pressure could be obtained at the cost of cerebral blood flow, particularly when intracranial pressure was significantly elevated. ${ }^{26}$ ) DeRougement et al. were wise enough not to fall in the risk of uncontrolled hypocapnea. ${ }^{5)}$ Patients were placed in only mild hypocapnea when the brain vasomotor index (mean intracranial pressure/mean arterial blood pressure) was below 0.25 , and $\mathrm{PaCO}_{2}$ was kept within normal limits when the index was above 0.25 . Becker et al. ${ }^{2)}$ conducted well programmed studies in patients treated under controlled ventilation and discussed their results in comparison with other large series. Thirty six percent of their patients were categorized as good recovery, $24 \%$ as moderate disability, $8 \%$ as severe disability, $2 \%$ as vegetative, and $30 \%$ as death. They emphasized the increased number of patients with good recovery by this technique and also that their efforts had not resulted in increased vegetative or severe disability cases. Mortality and the number of vegetative cases were similar to our results, although functional recovery seems to be better in our series. Becker et al. concluded that the maximum effect of controlled ventilation was in protection from secondary hypoxic brain damage rather than reduction of intracranial pressure. Their remarks remind us of our experiences in animal experiments. That is when intracranial hypertension is produced under controlled respiration, the animal continues to show a variety of dramatic phenomenon known as vasomotor paralysis until cardiac arrest, but if the same situation is produced under spontaneous breathing, the animal rapidly deteriorates, showing abnormal respiratory pattern and dies before the relevant data are obtained. Moody et al. ${ }^{19}$ ) produced intracranial hypertenstion in two groups of dogs by expansion of an epidural balloon. All of their 10 animals in the control group died within 12 hours after discontinuation of the respirator, but 7 of 10 widely decompressed dogs survived more than 10 days without respiratory control. From this data, the importance of decompressive craniectomy is evident, at least for short-term survival.

Once the patient has deteriorated and is in a terminal stage after unsuccessful conservative therapy, namely when intracranial pressure is wavering in accordance with oscillation of systemic blood pressure (as in Stage IV of Langfitt ${ }^{121}$ ), or pressure of the brain tissue overcomes that of the cerebral veins (Hayashi, et al. $\left.^{9}\right)$, all treatments are futile. Large decompressive craniectomy would not bring about any better results, but rather ends in rupture of arachnoid and pia mater by the ballooning hemispheres. Decompressive craniectomy is not of help in such a situation as it should have been performed at the appropriate time if maximum benifits are to be expected. Thus, at this point, there is no purpose in monitoring intracranial pressure for determining the indication of decompressive craniectomy.

Twenty six cases of acute brain swelling were analyzed by Ogawa et al. ${ }^{20}$ ) All of their cases required removal of bone flap because of rapid brain bulging; brain death occurred after an average of 28 hours from surgey. Twenty three patients $(89 \%)$ died and $3(11 \%)$ became vegetative. Once the state of acute brain swelling is established, there are no known means for effective treatment. Most of such patients in our series were from the group of poor prognostic scale, where the progressive vicious cycle of impaired brain metabolism secondary to increased intracranial pressure and poor circulation were likely to occur. However, the problem is not yet settled with regard to children who are preoperatively in good condition, but who die due to acute brain swelling. Lindenberg et al. ${ }^{13}$ ) reported generalized brain swelling involving supra- and infratentorial structure and stressed the specific features of head injury in children.

In spite of recent development of various treatments for severe head injury, large de- 
compressive craniectomy has proven to play an indispensable role as a basic surgical procedure. Our follow-up study has confirmed that satisfactory results, which could be favorably compared with any other large series, have been obtained not only in survival rate but also in functional recovery.

\section{References}

1) Araki, C. and Matsumoto, S.: Autopsy study on 933 fatal head injuries. Brain and Nerve Injury (Tokyo) 2: 131-137, 1970.

2) Becker, P., Miller, J. D., Jr., Greenberg, R. P., Young, H. F. and Sakalas, R.: The outcome from severe head injury with early diagnostic and intensive management. $J$ Neurosurg 47 : 491-502, 1977.

3) Cooper, P. R., Rovit, R. L. and Ransohoff, $\mathrm{J}$.: Hemicraniectomy in the treatment of acute subdural hematoma: A reappraisal. Surg Neurol 5: 25-28, 1976.

4) Courville, C. B.: Contrecoup injuries of the brain in infancy. Arch Surg 90: 157-165, 1965.

5) de Rougemont, J., Benabid, A. L. Chirossel, J. P. and Barge, M.: The brain vasomotor tone index as prognosis leader in severe head injuries. pp 119-126, In Beks, J.W.F., Bosch, D. A. and Brock, M. (eds): Intracranial pressure III. Springer-Verlag, Berlin, Heidelberg, New York, 1976.

6) Fell, D. A., Fitzgerald, S., Moiel, R. H. and Caram, P.: Acute subdural hematomas. Review of 144 cases. $J$ Neurosurg 42: 37-42, 1975.

7) Grumme, Th., Lanksch, W., Kazner, E. and Meese, W.: The value of computed tomography for diagnosis and treatment of severe closed head injuries. Excerpta Medica. Int. Cong. Series No. 418. 6th International Congress of Neurological Surgery. 1977, $112 \mathrm{p}$.

8) Gurjian, E. S. and Thomas, I. M.: Surgical management of the patient with head injury. Clin Neurosurg 12: 56-74, 1964.

9) Hayashi, N., Takeuchi, T., Sugawara, T., Goto, T., Tsubokawa, T. and Moriyasu, N.: The alteration of perfusion pressure and cerebral circulation during intracranial hypertension caused by inflation of balloons in the infra- and supra-tentorial spaces. Neurol Med Chir 16 (part II): 515-524, 1976.

10) Jennett, B.: Importance of ICP monitoring in clinical management of patient with intracranial lesions. pp 493-495, In Lundberg, N., Pontén, U. and Brock, M. (eds): Intracranial
Pressure II. Springer-Verlag, Berlin, Heidelberg, New York, 1975.

11) Kerr, F. W. L.: Radical decompression and dural grafting in severe cerebral edema. Proc Staff Meet Mayo Clin 43: 852-864, 1968.

12) Langfitt, T. W., Weinstein, J. D. and Kassell, N. F.: Cerebral vasomotor paralysis produced by intracranial hypertension. Neurology 15: 622-641, 1965.

13) Lindenberg, R., Fisher, R. S., Durlacher, S., Lovitt, W. V., Jr. and Freytag, E.: The pathology of the brain in blunt head injuries of infants and children. Int Congr Neuropath II : 477-479, 1955.

14) Makino, H., Uemura, K., Yamaura, A., Takeshima, T., Ryu, H. and Ninchoji, T.: Our attitude toward surgical management of severe cerebral contusion. $J$ Chiba Med Soc 44: 344-350, 1968.

15) Makino, H., Uemura, K., Yamaura, A., Ninchoji, T. Ryu, H., Takeshima, T. and Okawa, H.: Surgical management of severe head injury in childhood (1). J Chiba Med Soc 45: 345-349, 1969.

16) Makino, H., Uemura, K., Horie, T. and Yamaura, A.: Treatment of acute subdural hematoma. Neurological Surgery (Tokyo) 3: 7-14, 1975.

17) Makino, H., Nakada, Y., Kono, M. and Watanabe, Y.: Acute traumatic intracranial hematoma in infancy and childhood. Neurol Med Chir 17 (Part II): 187-193, 1977.

18) McLaurin, R. L. and Tator, F. T.: Acute subdural hematoma. Review of 90 cases. $J \mathrm{Neu}$ rosurg 18: 61-67, 1961.

19) Moody, R. A., Ruamsuke, S. and Mullan, S. F.: An evaluation of decompression in experimental head injury. $J$ Neurosurg 29: 586-590, 1968.

20) Ogawa, M., Minami, T. and Katsurada, K.: Limited effects of decompressive craniectomy in acute brain swelling. Brain and Nerve Injury (Tokyo) 5: 93-103, 1973.

21) Ohta, T., Waga, S., Handa, H., Saito, I., Takeuchi, K., Suzuki, J. and Takaku, A.: New grading of level of disordered consciousness. Neurological Surgery (Tokyo) 2: 623627, 1974.

22) Overgaard, J., Christiansen, S., Hvid-Hansen, O., Haase, J., Land, A. M., Hein, O., Pedersen, K. K. and Tweed, W. A.: Prognosis after head injury based on early clinical examination. Lancet II: 631-635, 1973.

23) Ransohoff, J. and Randt, C. T.: Profiles of fatal and nonfatal closed head injury. Excerpta Medica. Int. Cong. Series. No. 110. 
3rd International Congress of Neurological Surgery. 1965, pp 137-142.

24) Ransohoff, J., Benjamin, V., Gage, E. L., Jr. and Epstein, F.: Hemicraniectomy in the management of acute subdural hematoma. $J$ Neurosurg 34: 70-76, 1971.

25) Richards, T. and Hoff, J.: Factors affecting survival from acute subdural hematoma. Surgery 75: 253-258, 1974.

26) Rudenberg, F. H., McGrow, C. P. and Tindall, G. T.: Effects of hyperventilation, $\mathrm{CO}_{2}$, and CSF pressure on internal carotid blood flow in the baboon. $J$ Neurosurg $44: 347-352,1976$.

27) Sano, K.: Survey of the organization of services for the treatment of acute head injury in Japan. Excerpta Medica. Int. Cong. Series. No. 93. 3rd International Congress of Neurological Surgery. 1965, pp 23-27.

28) Sugiura, K., Kanazawa, C., Sato, S., Kondo, S., Muraoka, K. and Nishimura, N.: A clinical study on a system of assessment of impaired consciousness. Brain and Nerve 29: 879-884, 1977.

29) Sugimoto, H., Shimazaki, S., Takahashi, M. and Sawada, Y.: Use of hypertonic lactated Ringer solution in treatment of acute serious head injuries. Presented in 36th Annual Meeting of The Japan Neurosurgical Society, 1977.

30) Talalla, A. and Morin, M.: Acute traumatic subdural hematoma. A review of 100 consecutive cases J Trauma 11:771-777, 1971.

31) Vapalathi, M. and Troupp, H.: Prognosis for patients with severe brain injuries. $\mathrm{Br} \mathrm{Med} J$ 3: 404-407, 1971.

32) Venes, J. L. and Collins, W. F.: Bifrontal decompressive craniectomy in the management of head trauma. $J$ Neurosurg 42: 429-433, 1975.

33) Yamaura, A., Uemura, K. and Makino, H.: Large decompressive craniectomy for severe cerebral contusion. Analysis of 90 cases. Brain and Nerve Injury (Tokyo) 3: 517-528, 1971.

34) Yamaura, A., Uemura, K. and Makino, H.: Large decompressive craniectomy for severe cerebral contusion. Excerpta Medica. Int. Cong. Series No. 418 6th International Congress of Neurological Surgery. 1977, $290 \mathrm{p}$. 